\title{
Long-term effects of prenatal indomethacin administration on the pulmonary circulation in rats
}

\author{
J. Herget*, V. Hampl*, V. Povýšilová**, Z. Slavík ${ }^{+}$
}

Long-term effects of prenatal indomethacin administration on the pulmonary circulation in rats. J. Herget, V. Hampl, V. Povýśilová, Z. Slavík. @ERS Journals Ltd 1995.

ABSTRACT: Mechanical properties of the adult pulmonary vasculature are affected by perinatal experience of hypoxic pulmonary hypertension. In the present study, we followed the long-term effects of perinatal pulmonary hypertension induced by means other than hypoxia in rats.

Daily injections of indomethacin $\left(1 \mathrm{mg} \cdot \mathrm{kg}^{-1}\right.$ body weight $\left.(\mathrm{BW})\right)$ were given to the parturient rats. Their newborn pups had significantly increased number of muscularized peripheral pulmonary vessels. Pulmonary hypertension, however, did not persist to adulthood (mean pulmonary arterial pressure (Ppa) was 17.2 \pm 1.3 torr in the experimental group and 16.4 \pm 0.8 torr in controls). Pulmonary hypertension induced in adult rats by exposure to chronic hypoxia or by acute hypoxic challenges was similar in indomethacin-treated and control rats. Normoxic perfusion pressure/ flow $(\mathbf{P} / \dot{\mathbf{Q}})$ plots in isolated lungs were less steep in indomethacin-treated than in control rats. Acute hypoxia increased the slope of $\mathbf{P} / \dot{Q}$ plots in indomethacin treated rats but not in controls.

The described changes in the pulmonary vasculature induced by indomethacin are similar to those found previously in adult rats born in hypoxia. We conclude that perinatal pulmonary hypertension permanently modifies the pulmonary vasculature.

Eur Respir J., 1995; 8, 209-215.

\begin{abstract}
Depts of *Physiology and **Pathology, 2nd Medical School, Charles University, Prague, Czech Republic. ${ }^{+}$Center of Pediatric Cardiology and Surgery, University Hospital Motol, Prague, Czech Republic.
\end{abstract}

Correspondence: J. Herget, Dept of Physiology, 2nd Medical School, Charles University Prague, Plzen̆ská 130, 15000 Praha 5, Czech Republic

Keywords: Cyclo-oxygenase inhibition, development of pulmonary blood vessels, hypoxia, hypoxic pulmonary vasoconstriction, pulmonary hypertension, rat

Received: February 71994

Accepted after revision October 181994

This study was supported in part by a grant from the Czech Ministry of Health No. MZdr C̆R No. 0599-3, and in part by a grant from GAC̆R No. 0500-3.
Exposure to hypoxia for several days in the perinatal period induces permanent changes of the pulmonary circulation. In isolated lungs of adult rats born in hypoxia but raised in normal atmospheric air, the perfusion pressure/flow $(\mathrm{P} / \dot{\mathrm{Q}})$ relationship is altered $[1,2]$. In addition, during recovery after sojourn in a hypoxic chamber in adulthood, the pulmonary hypoxic vasoconstriction is greater in rats born in hypoxia than in rats born in room air [3]. We wondered whether these delayed changes are a specific effect of the lack of oxygen in the perinatal period, or if a different perinatal intervention affecting the pulmonary blood vessels would have similar long-lasting effect. Therefore, we studied the pulmonary circulation of adult rats whose mothers were repeatedly injected with indomethacin during the last 3 days of pregnancy. Indomethacin, like hypoxia, is known to induce pulmonary hypertension in the near-term foetus [4].

\section{Methods}

\section{Experimental groups}

Fourteen pregnant female Wistar specific pathogenfree $(\mathrm{SPF})$ rats were injected with indomethacin $\left(1 \mathrm{mg} \cdot \mathrm{kg}^{-1}\right.$ body weight $(\mathrm{BW})$ once daily, on each of the last 3 days before expected delivery). Three dams delivered immediately after the third injection, the other two did not deliver until 3 or 5 days after the indomethacin injections. All of these animals were excluded from the study. The remaining nine rats delivered during the night following the day of the last injection. Their pups (males only were used) were randomly divided in four groups (fig. 1).

Animals in Group I-0 were sacrificed during the first postnatal day for morphological study. The remaining rats were weaned at the age of 1 month. It was not possible, for technical reasons, to perform the whole set of measurements in one animal and, therefore, either the haemodynamic measurement in vivo and lung morphological evaluation, or measurements in the preparation of isolated perfused lungs, were performed in adult rats.

Animals in Group I-10 were studied when they were 10 weeks old. A part of the group was used for the preparation of isolated perfused lungs and the other part for the measurement of pulmonary arterial blood pressure ( $\overline{\mathrm{P}} \mathrm{pa})$ and for morphological evaluation.

Rats in Groups I-12 and I-14 were exposed for two weeks to normobaric hypoxia (fractional inspiratory oxygen $\left(\mathrm{FIO}_{2}\right)$ 0.1) in an isobaric hypoxic chamber at the age of 10 weeks. In six animals, the Ppa was measured immediately after the exposure (I-12). The remaining animals (I-14) were allowed to recover in the room air 

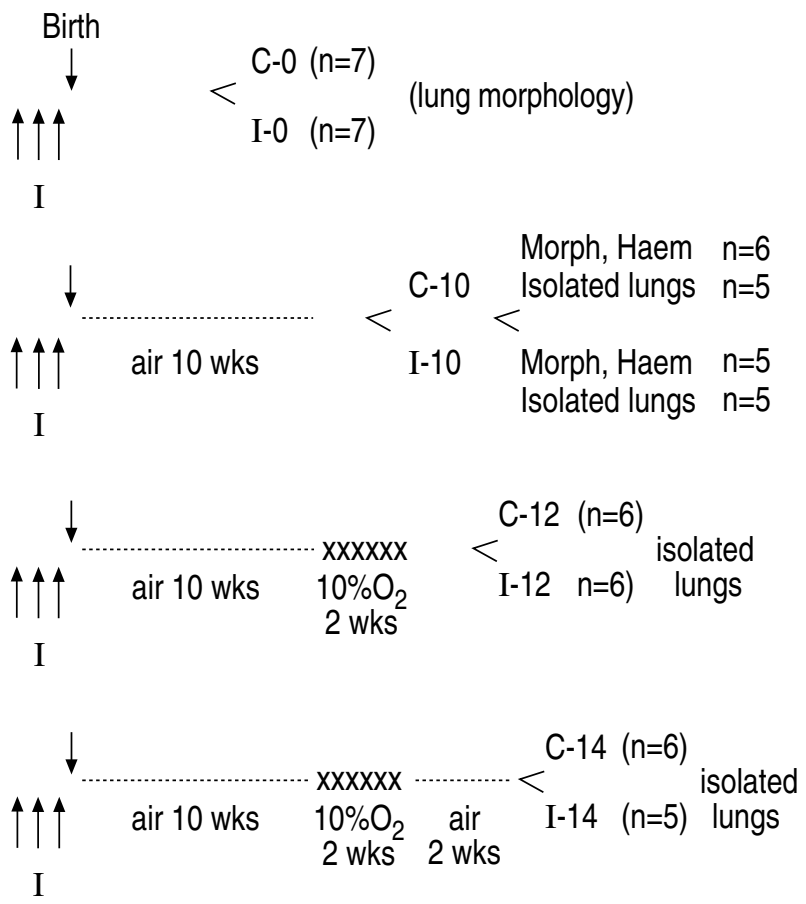

Fig. 1. - Schematic representation of protocols used. See text for explanation of groups. C: controls pregnant females not treated; I: Prenatal indomethacin treated, daily injection of pregnant female for 3 days pre-term; Morph: morphology; Haem: haemodynamics.

for an additional 2 weeks and the hypoxic reactivity of their pulmonary vessels was measured in isolated lungs.

Rats of the corresponding control groups, C-0, C-10, $\mathrm{C}-12$ and $\mathrm{C}-14$, were the offsprings of rats that received no treatment in pregnancy. They were kept in the same conditions as the rats in the experimental groups. The numbers of animals in experimental and control groups are given in the fig 1 .

\section{Morphological analysis}

Newborn rats (Groups I-0 and C-0) were killed in ether anaesthesia by decapitation. Their chest was opened, and lungs and heart were removed and placed into $10 \%$ neutral formaldehyde solution for several days. Lungs of adult rats (Groups I-10, I-12, C-10 and C-12) were dissected after the $\bar{P}$ pa measurement was finished. After the rats were killed with thiopental overdose, the trachea was cannulated and the chest was opened. Lungs were filled with $10 \%$ formaldehyde solution via the trachea under a hydrostatic pressure of $12 \mathrm{cmH}_{2} \mathrm{O}$. The heart was cut into parts, using the method of Fulton et al. [5], and the relative weight of the right ventricle was estimated. The lungs were then placed in formaldehyde solution for several more days. The lung tissue was cut into 5-7 $\mu \mathrm{m}$ thick sections and stained with haematoxylin and eosin in combination with staining elastic fibres, blue trichrome, Alcian blue and periodic acid-Schiff (PAS) reaction, and impregnation of reticular fibres. Sections were examined under light microscopy, and the relative number of peripheral pulmonary blood vessels with thick muscular wall was estimated using the method described by Hunter et al. [6].

\section{Blood pressure measurement}

The pulmonary artery was catheterized in rats from Groups I-10, C-10, I-12 and C-12, using the method described previously [7], in thiopental anaesthesia (60 $\mathrm{mg} \cdot \mathrm{kg}^{-1} \mathrm{BW}$, i.p.).

\section{Isolated lung preparation}

Isolated lungs were prepared, as described previously [3], in some of the animals from Groups I-10 and C-10 (rats not used for the Ppa measurement) and in Groups I-14 and C-14. Rats recovering from the exposure to chronic hypoxia (I-14 and C-14) were chosen for the measurements of hypoxic pulmonary vascular reactivity, because the hypoxic pulmonary vasoconstriction in rats studied immediately after sojourn in a hypoxic chamber (Groups I-12 and C-12) is substantially blunted [3, 8]. The rats were anaesthetized with thiopental (100 $\mathrm{mg} \cdot \mathrm{kg}^{-1} \mathrm{BW}$, i.p.) and ventilated via tracheostomy, with air $+5 \% \mathrm{CO}_{2}$ at 65 breaths. $\mathrm{min}^{-1}$. Peak inspiratory and expiratory pressures were 9 and $2.5 \mathrm{cmH}_{2} \mathrm{O}$, respectively. Following the sternotomy and heparinization the pulmonary artery and left ventricle were cannulated. Lungs and heart were removed from the chest en bloc, suspended in a humid and thermoregulated chamber $\left(38^{\circ} \mathrm{C}\right)$, and perfused with blood at a rate of $0.06 \mathrm{ml} \cdot \mathrm{min} \cdot \mathrm{g}^{-1}$ $\mathrm{BW}$. The blood for the perfusion was obtained by cardiac puncture from 2-3 rat blood donors under ether anaesthesia.

After the onset of perfusion, the lungs were first allowed to stabilize for $20 \mathrm{~min}$ and were then challenged with two periods of hypoxia $\left(3 \% \mathrm{O}_{2}\right.$ for $10 \mathrm{~min}$, at $10 \mathrm{~min}$ interval). All gas mixtures in this study contained 5\% $\mathrm{CO}_{2}$ and were balanced with nitrogen. The first two hypoxic challenges were used to establish a constant hypoxic reactivity of the preparation [9]. After another 10 min of normoxic gas, the measurement of the hypoxic reactivity was started. It consisted of $10 \mathrm{~min}$ challenges of ventilation with mixtures containing 10, 5, 3 and $0 \%$ of $\mathrm{O}_{2}$ (in this order) separated with 10 min intervals of normoxic ventilation. As the perfusion flow rate, outflow pressure $\left(-2.5 \mathrm{cmH}_{2} \mathrm{O}\right)$, and parameters of ventilation were held constant, any increase of perfusion pressure reflected vasoconstriction. The difference between the maximal perfusion pressure achieved during the hypoxic challenge and perfusion pressure before the challenge $(\Delta \mathrm{P})$ was the measure of the vasoconstrictor response to the respective hypoxic challenge.

In Groups I-10 and C-10, the perfusion pressure-flow $(\mathrm{P} / \mathrm{Q})$ relationship [1], was measured, in addition to the hypoxic reactivity evaluation. The perfusion pump was stopped for $30 \mathrm{~s}$, and then the perfusion flow was increased in 4-5 steps (30-90 s each) up to $32-37 \mathrm{ml} \cdot \mathrm{min}^{-1}$. The baseline perfusion flow was then adjusted again for 
$5 \mathrm{~min}$, the lungs challenged with hypoxia $\left(3 \% \mathrm{O}_{2}\right)$, and on top of the hypoxic response the procedure of $\mathrm{P} / \mathrm{Q}$ measurement was repeated.

\section{Statistics}

Body weights, baseline perfusion pressures in isolated lungs, $\overline{\mathrm{P}} \mathrm{pa}$ and relative weights of the right ventricle were compared between the groups using oneway analysis of variance (ANOVA) and Scheffé test [10]. The magnitude of vasoconstrictor responses to hypoxic stimuli were evaluated by twoway ANOVA and Student-NewmanKeuls test for simultaneous multiple comparisons [10]. Perfusion $\mathrm{P} / \mathrm{Q}$ data were analysed with linear regression. In all cases, the relationship was found to be linear ( $r \geq 0.964)$. Therefore, the relationship was described by its slope and extrapolated intercept with the pressure axis. Differences in these parameters between the groups were evaluated by unpaired t-test, and the differences induced by hypoxia in one animal by paired t-test. Values of $p<0.05$ were considered significant. The results are presented as means \pm SEM.

\section{Results}

\section{Morphological evaluations}

The lung tissue of the newborn control rats (Group C-0) showed regularly expanded alveoli throughout the whole width of the section, including the subpleural space (fig. 2a). The lumen of an alveolus was usually empty, only exceptionally containing scarce erythrocytes. The lumina of the respiratory bronchioles were circular. Intra-alveolar septa were thin and well-formed, with a relatively small number of cells. Collapsed areas were extremely rare.

By contrast, in the lung tissue of the newborn rats whose mothers were injected with indomethacin (Group I-0), extensive collapsed areas, mostly expressed in subpleural region, prevailed (fig. 2b). The lumina of the respiratory bronchioles were frequently extensively deformed. The lung tissue consisted of areas of more or less collapsed alveoli containing oedematous fluid rich in erythrocytes, as well as of alveoli that appeared extensively expanded. The thickness of the interalveolar septa was frequently enhanced. They contained numerous cells and their capillaries appeared dilated. The ratio of the number of thick-walled to all distal pulmonary vessels was significantly higher in the newborn indomethacin-treated group than in newborn controls (fig. 3 , newborn).

The morphological appearance of the lungs of rats from Groups I-10 and C-10 did not differ, and the relative number of thick-walled distal pulmonary vessels was similar (fig. 3, adult). In the lungs of both groups of rats exposed to chronic hypoxia, the percentage of thickwalled distal pulmonary blood vessels was significantly increased. It was $21.7 \pm 1.7 \%$ in Group C-12 and a

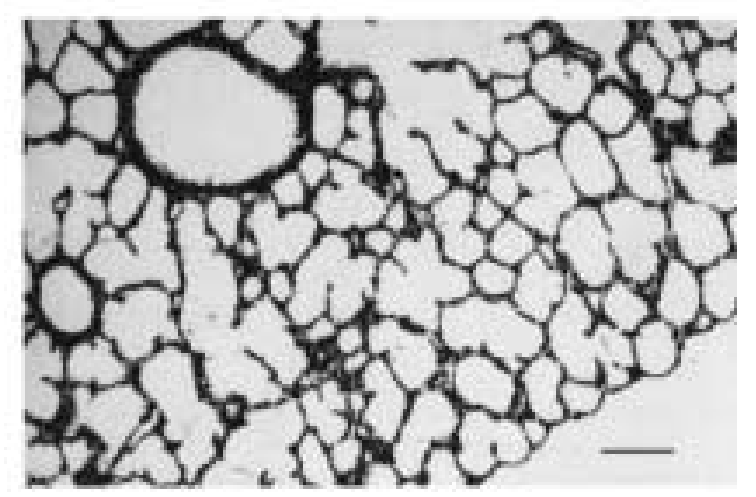

b

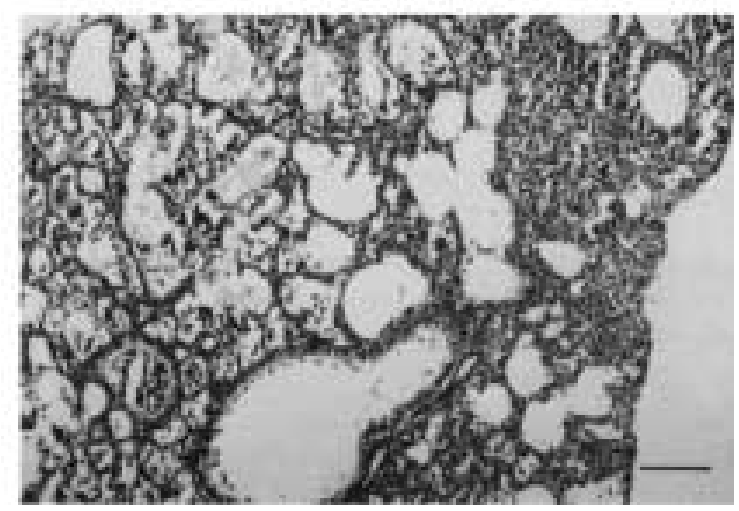

Fig. 2. - Lungs of control and indomethacin-treated newborn rats. a) Lungs of the control newborn rat (Group C-0, table 1). Most alveoli are regularly expanded all the way to the pleura (bottom right). The alveolar lumina are empty. Respiratory bronchiolus (top left) has a circular lumen. (Stained with haematoxylin and eosin, magnification $120 \times$ ). b) Lungs of the newborn rat whose mother was repeatedly injected with indomethacin during pregnancy (Group I-0, table 1). The tissue consists mainly of collapsed regions (very frequent subpleurally, right) and irregular small groups of expanded alveoli. Many alveoli contain erythrocytes and oedematous fluid (left part of the panel). Some alveolar septa are thickened and more cellular. The shape of the respiratory bronchiolus (bottom) is irregular. (Stained with haematoxylin and eosin, magnification $120 \times$ scale bar: $100 \mu \mathrm{m})$.

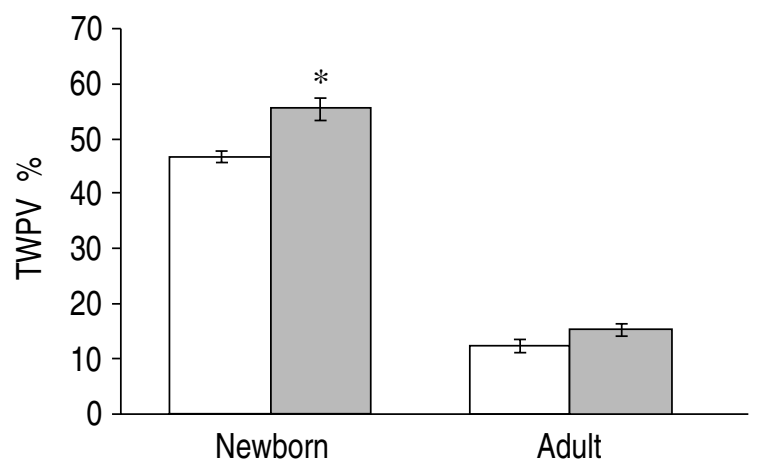

Fig. 3. - Percentage of muscularized peripheral pulmonary blood vessels in the lungs of control and indomethacin-treated rats. TWPV $\%$ : percentage of the thick-walled pulmonary blood vessels from the total number of distal pulmonary blood vessels in the slide in Groups C-0 and I-0 (newborn) and C-10 and I-10 (adult). $\square$ : controls; $\square$ : indomethacin. Range of number of vessels counted per slide in C-0 was 42-99, in I-0 18-47, in C-10 37-84 and in I-10 92-105. *: $\mathrm{p}<0.05$. 
Table 1. - Body weight, mean pulmonary artery blood pressure and the relative weight of the right heart ventricle in controls and indomethacin-treated rats living in air and exposed to hypoxia

\begin{tabular}{llll}
\hline Group & $\begin{array}{c}\text { BW } \\
\mathrm{g}\end{array}$ & $\begin{array}{c}\text { Ppa } \\
\text { torr }\end{array}$ & $\mathrm{RV} / \mathrm{LV}+\mathrm{S}$ \\
\hline $\mathrm{C}-10$ & $284 \pm 5.3$ & $16.4 \pm 0.8$ & $0.259 \pm 0.014$ \\
$\mathrm{I}-10$ & $277 \pm 10.1$ & $17.2 \pm 1.3$ & $0.257 \pm 0.018$ \\
C-12 & $285 \pm 6.9$ & $34.6 \pm 4.3^{*}$ & $0.398 \pm 0.022^{*}$ \\
$\mathrm{I}-12$ & $274 \pm 6.2$ & $30.7 \pm 4.7^{*}$ & $0.474 \pm 0.034^{*+}$ \\
\hline
\end{tabular}

Data are presented as mean \pm SEM. For the explanation of groups see fig. 1. BW: body weight; Ppa: mean pulmonary arterial blood pressure; $\mathrm{RV} / \mathrm{LV}+\mathrm{S}$ : relative weight of the right ventricle (weight of the right ventricle/sum of the weights of the left ventricle and heart septum). Values of $\mathrm{p}<0.05, *$ : C-12 vs C10, I-12 vs I-10; +: C-12 vs I-12.

$23.2 \pm 2.0 \%$ in Group I-12 ( $<<0.05$ when compared with relevant controls C-10 and I-10). Groups C-12 and I12 , however, did not differ.

\section{Pulmonary artery blood pressure}

The $\bar{P}$ pa and the relative weight of the right ventricle were similar in adult controls (C-10) and in those whose mothers were treated with indomethacin (I-10) (table 1). Also, exposure to chronic hypoxia did not induce more severe pulmonary hypertension in indomethacin-treated rats, though the right ventricle gained significantly more weight during the exposure to hypoxia (table $1)$.

\section{Reactivity to hypoxia}

In isolated lung preparations, the baseline perfusion pressure before the measurement of the dose-response to acute hypoxic challenges was $16.8 \pm 0.6$ torr in Group C10 and $12.9 \pm 1.1$ torr $(\mathrm{p}>0.05)$ in the corresponding indomethacin-treated rats (Group I-10). After the exposure to 2 weeks of hypoxia and following recovery, the baseline perfusion pressure again did not differ, being $17.4 \pm 1$ torr in C-14 and $14.0 \pm 0.9$ torr in $\mathrm{I}-10$ groups.

The reactivity to acute hypoxic stimuli is shown in figure 4. In all cases, the magnitude of the responses were significantly dependent on the degree of hypoxia; more severe hypoxia produced more vigorous response. The pressure differences induced by acute hypoxic challenges were slightly, but significantly, higher in both groups recovering from chronic hypoxic exposure (C-14 and I-14) than in the groups not exposed to chronic hypoxia (C-10 and I-10). However, the differences in the hypoxic reactivity caused by prenatal treatment with indomethacin (I-10 vs C-10 and $\mathrm{I}-14$ vs $\mathrm{C}-14)$ were not significant.

\section{Perfusion $P / \dot{Q}$ relationship}

The baseline perfusion pressure before the measurements of vascular pressure/flow relationship in control
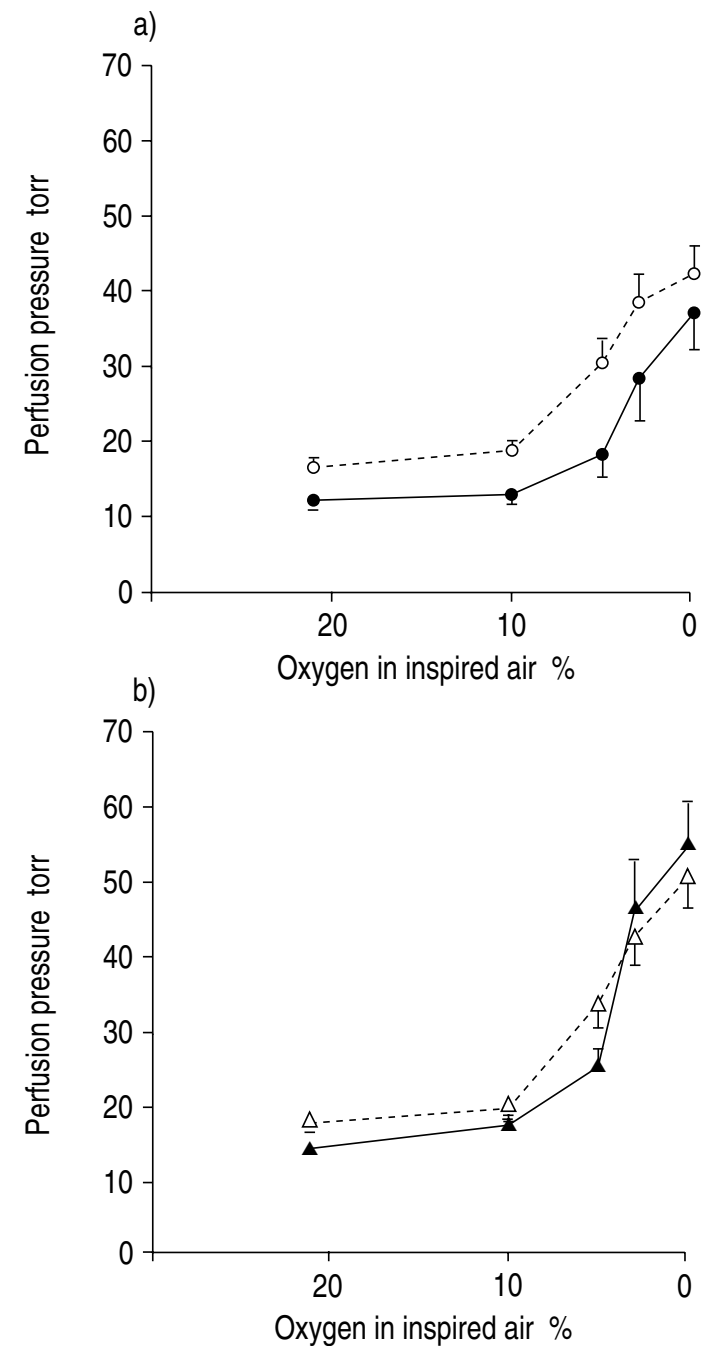

Fig. 4. - Dose-response to acute hypoxia in isolated lungs. a) Rats investigated at the age of 10 weeks (Groups I-10 $(n=5)$ and C-10 $(n=5)$, see table 1). b) Fourteen week old rats recovering from hypoxic exposure (Groups C-14 $(n=6)$ and I-14 $(n=5)$, see table 1). Vertical bars represent SEM. Two-way analysis of variance (ANOVA) indicated a significant relation between the pressor response and degree of acute hypoxia in all groups. The responses $(\Delta \mathrm{P})$ of Groups C-14 and I-14 are significantly bigger than those of Groups $\mathrm{C}-10$ and I-10, respectively, but there is no significant difference between the control and indomethacin-treated groups. -- -O---: Group C-10; $\longrightarrow$ : Group I-10. $---\Delta---$ : Group C-14; $\_$: Group I-14.

rats $(\mathrm{C}-10=20.9 \pm 0.9$ torr $)$ and prenatally indomethacintreated rats $(\mathrm{I}-10=19.4 \pm 2.0$ torr) were not significantly different. The perfusion $\mathrm{P} / \mathrm{Q}$ plots are presented in figure 5 , and the results of the linear regression analysis of this relationship are given in table 2 . When the isolated lung preparations were ventilated with the normoxic gas mixture, the values of the extrapolated pressure axis intercept did not differ significantly between the groups. The slope, however, was significantly lower in prenatally indomethacin-treated rats than in control rats. Changes in the $\mathrm{P} / \mathrm{Q}$ relationship elicited by acute hypoxic challenge also differed between the groups (fig. 5). In controls (Group C-10), acute hypoxia significantly enhanced the pressure axis intercept, but did not alter the slope. By contrast, in the rats treated prenatally with indomethacin 
a) $\mathrm{C}-10$

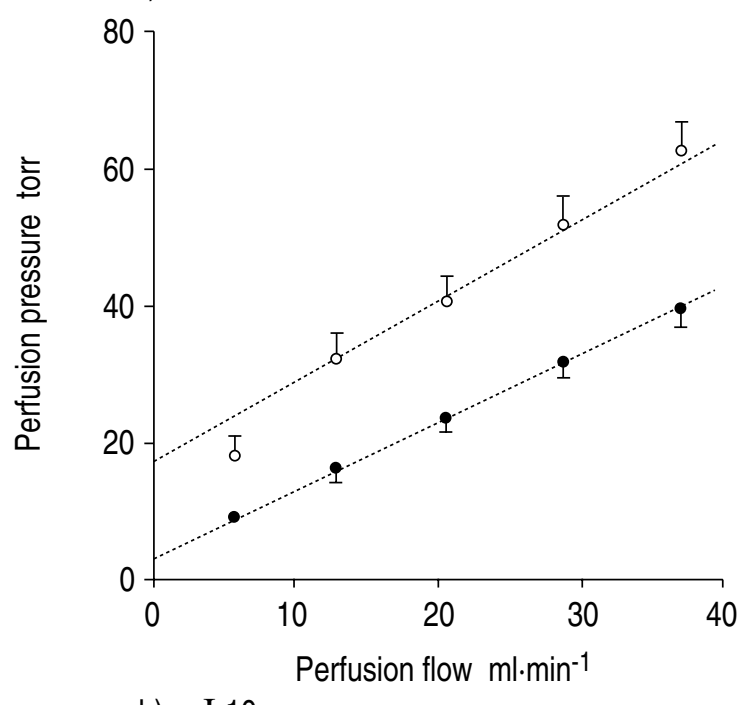

b) $\mathrm{I}-10$

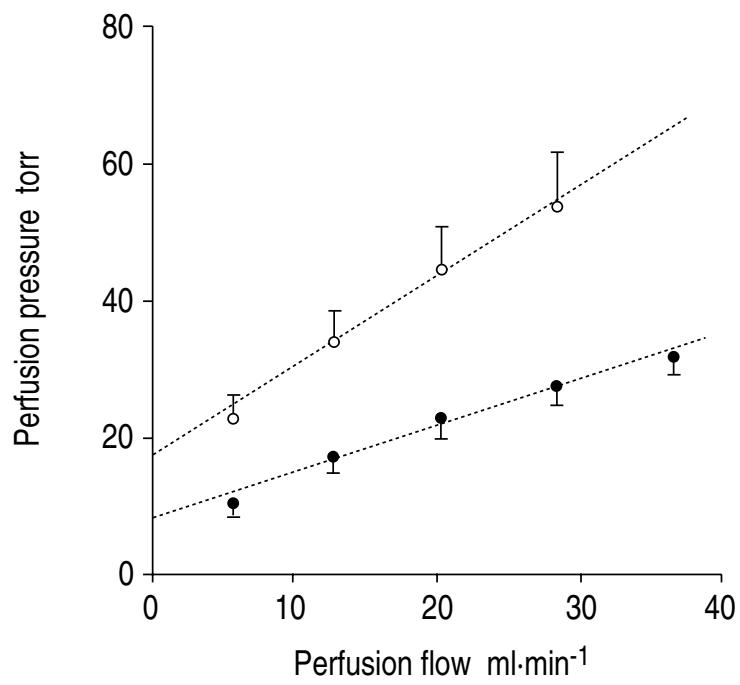

Fig. 5. - Perfusion pressure/flow plots in isolated lungs. a) Control group, C-10. b) Indomethacin-treated group, I-10. Closed and open symbols show individual values obtained during normoxic ventilation $\left(\mathrm{FIO}_{2}=0.21\right)$ and acute hypoxic ventilation $\left(\mathrm{FIO}_{2}=0.03\right)$, respectively. Vertical bars represent SEM. The statistical significance of the relationship is given in table 3 . $\bullet$ normoxia; $\bigcirc$ : hypoxia.

Table 2. - Results of linear regression analysis of pulmonary vascular pressure-flow data in control rats and rats treated prenatally with indomethacin

\begin{tabular}{|c|c|c|c|c|c|}
\hline \multirow{2}{*}{\multicolumn{2}{|c|}{ Group $_{n}$}} & \multicolumn{2}{|c|}{$\mathrm{FIO}_{2}=0.21$} & \multicolumn{2}{|c|}{$\mathrm{FIO}_{2}=0.03$} \\
\hline & & $\begin{array}{l}\mathrm{P}_{0} \\
\text { torr }\end{array}$ & $\begin{array}{l}\mathrm{P} / \dot{\mathrm{Q}} \\
\text { torr } \cdot \mathrm{ml} \cdot \mathrm{min}^{-1}\end{array}$ & $\begin{array}{l}\mathrm{P}_{0} \\
\text { torr }\end{array}$ & $\begin{array}{c}\mathrm{P} / \mathrm{Q} \\
\text { torr } \cdot \mathrm{ml} \cdot \mathrm{min}^{-1}\end{array}$ \\
\hline C-10 & 6 & $3.94 \pm 0.84$ & $0.98 \pm 0.05$ & $19.16 \pm 4.87 *$ & $1.17 \pm 0.21$ \\
\hline I-10 & 5 & $7.86 \pm 2.04$ & $0.67 \pm 0.04^{\#}$ & $16.36 \pm 2.43 *$ & $1.32 \pm 0.21 *$ \\
\hline
\end{tabular}

Data are presented as mean \pm SEM. For the denomination of the groups see fig. 1. $\mathrm{P}_{0}$ : extrapolated intercept with the pressure axis; $\mathrm{P} / \mathrm{Q}$ : slope of the perfusion pressure/flow plot; $\mathrm{FIO}_{2}$ : functional inspiratory oxygen. *: values measured at $\mathrm{FiO}_{2}=0.03$ are significantly different $(\mathrm{p}<0.05)$ from measurements at $\mathrm{FIO}_{2}=0.21$; \#: significant $(\mathrm{p}<0.05)$ difference between the groups $\mathrm{C}-10$ and $\mathrm{I}-10$.
(Group I-10), the decrease of oxygen content in ventilation gas mixture significantly increased both the pressure axis intercept and the slope of the $\mathrm{P} / \mathrm{Q}$ relationship.

\section{Discussion}

The present study shows that prenatal treatment with indomethacin has long-lasting consequences for lung vessels. We did not evaluate the influence of indomethacin on pulmonary haemodynamics in the foetus. Prior to the discussion of our findings, therefore, we will address the presumed effects of indomethacin in the prenatal period.

The patency of the ductus arteriosus is actively preserved by a dilatory action of prostaglandin $E_{2}$ [11]. After blocking of prostaglandin synthesis by inhibitors of cyclo-oxygenase, the ductus arteriosus constricts [12-14]. Indomethacin is particularly effective [13]. In rats investigated in the last 3 days of gestation, the ductus arteriosus remains constricted for about $24 \mathrm{~h}$ after indomethacin administration $[14,15]$.

Impaired patency of the foetal ductus arteriosus enhances the pulmonary blood flow and pressure. Hypertensive changes of pulmonary blood vessels were found following mechanical compression of the ductus arteriosus $[16,17]$. Similar effects appeared after the constriction of the duct by indomethacin $[4,18]$. The possibility of a direct influence of indomethacin on pulmonary blood vessels in addition to the indirect action via closure of the ductus arteriosus was also raised [19]. Catheterization studies in foetal lambs showed that a single dose of indomethacin produced a significant increase in pulmonary arterial blood pressure, that persisted for several days [4].

The pups from the mothers injected with indomethacin in our study had lungs that showed substantial morphological abnormalities, and had significantly more thick-walled peripheral pulmonary blood vessels than the corresponding control group. An increase in the thickness of media in the wall of peripheral pulmonary vessels due to presence of smooth muscle cells is a typical feature in pulmonary hypertension [20].

For technical reasons, the lungs of newborn rats in our study were not expanded in the same way as the lungs of adults. They become leaky even at a low filling pressures. Inability to expand newborn lungs was one of the reasons why the method expressing the relative number of thick-walled blood vessels was preferred to the direct measurement of the thickness of media for the estimation of vascular wall muscularization.

The direct measurement of the pulmonary blood pressure in newborn rats is unrealistic, and a longitudinal study comparing the pattern of recession of the pulmonary vascular smooth muscle in these two groups would certainly provide more substantial information. Nevertheless, based on our findings supported by the results of studies mentioned above, we are confident that the offsprings of dams treated with indomethacin had pulmonary hypertension and pulmonary vascular injury. This hypertension, however, later disappeared because the 
pulmonary arterial blood pressure, baseline perfusion pressure in the preparation of isolated lungs and the relative weight of the right ventricle in adult rats from Group I-10 did not differ from the measurements in the control group (C-10). Indomethacin-treated rats did not develop more severe pulmonary hypertension then controls when they were exposed to hypoxic environment in adulthood.

A surprising finding was the more severe right heart hypertrophy in indomethacin-treated rats after hypoxic exposure. The relationship of this finding to the priming effect of experience of perinatal pulmonary hypertension on the development of right heart hypertrophy in adulthood may be speculated. We did not, however, find a similar potentiation of right heart hypertrophy in rats born in hypoxic environment [3]. We cannot exclude that the hypoxia and/or the increase of the pulmonary arterial blood pressure was more severe in indomethacintreated rats than in controls during their stay in a hypoxic chamber. Pulmonary artery blood pressure was measured after the end of exposure, when the rats breathed air.

The pattern of the perfusion P/Q plots indicates the existence of an alteration of adult pulmonary vascular bed by prenatal administration of indomethacin. In normoxia the slope of the $\mathrm{P} / \mathrm{Q}$ line was significantly lower in Group I-10 than in controls. According to the Starling resistor model of the pulmonary circulation [21], the lower slope may correspond to a higher compliance of the vascular wall, or a greater cross-sectional area of the pulmonary vascular bed. Chronic hypoxic pulmonary hypertension in rats is associated with a decrease in the pulmonary vascular compliance [22], due to the deposition of collagen, and the growth of smooth muscle cells in the vascular wall [20]. This effect may be even more pronounced in the perinatal period [23]. It is unlikely that indomethacin-induced pulmonary hypertension would have an opposite effect. An increase in the cross-sectional area of pulmonary vasculature is more a probable explanation of the decrease of the slope of $\mathrm{P} / \dot{\mathrm{Q}}$ plots in indomethacin-treated rats. Vascular wall injury associated with pulmonary hypertension [24] in the perinatal period may enhance the genesis of pulmonary peripheral vessels [25].

The slight increase in hypoxic vascular reactivity found during the recovery from chronic hypoxia (Groups C-14 and I-14) has been discussed previously [3].

In control rats, acute hypoxia induced a rise of perfusion pressure intercept but not of the slope of the P/Q lines. It suggests, according to the Starling resistor model, that hypoxic pulmonary vasoconstriction took place in the thin-walled collapsible portion of pulmonary vasculture only. That location of hypoxic pulmonary vasoconstriction was confirmed by direct micropunture measurements [26], analysis of data obtained by venous and arterial occlusion [27, 28], and also by angiographic evidence [29]. By contrast, the simultaneous rise of the slope and intercept during acute hypoxia in adult rats born to dams treated with indomethacin (Group I-10) indicates that both collapsible and noncollapsible segments constricted in response to acute hypoxia. The possible explanation is that part of the originally collapsible vessels had lost collapsibility, but the responsiveness to hypoxia had been preserved. Loss of collapsibility may result from the increased amount of connective tissue in the vascular wall. Synthesis of the vascular wall matrix protein [30], and fibroblast proliferation [31] are a consequence of the increased wall tension.

The similarity of the observed changes in the P/Q plots in the rats with prenatal administration of indomethacin and the changes induced by another perinatal intervention, hypoxia, is noteworthy. Our group $[1,3]$ and HAKIM and Mortola [2] have shown that a short period of perinatal hypoxia induces changes in the perfusion $\mathrm{P} / \dot{\mathrm{Q}}$ plot, which are similar to the findings in the present study in indomethacin-treated rats. In addition, the adult rats born in hypoxic environment were hyperreactive to acute hypoxic stimuli during their recovery from the two week period of hypoxia [3]. We reason that the long-lasting changes found after both perinatal hypoxia and prenatal application of indomethacin (changes of the P/Q relation) are caused by a factor common to these two interventions, namely the presence of pulmonary hypertension at the critical period of development of pulmonary vasculature. The changes appearing in hypoxic environment only (hypoxic hyperreactivity) are probably the specific consequence of the lack of oxygen at the time of birth. The mechanism is not known. We cannot exclude, however, the postnatal hypoventilation hypoxia in the indomethacin-treated group (I-0).

The present study, thus, complements previous investigations, and provides additional evidence that the properties and reactivity of the pulmonary vasculature in adults is related to the conditions in which the critical part of development of pulmonary vasculature, the period of birth, takes place. The increased pulmonary vascular pressure and possible injury and/or stimulation of structures of the pulmonary vascular wall are probably important factors determining the pattern of the function of pulmonary blood vessels in adulthood.

\section{References}

1. Herget J, Hampl V. Pulmonary vasculature of adult rats is influenced by perinatal experience of hypoxia. Pulmonary blood vessels in lung disease. In: Progress In Respiratory Research 1990; 26: pp. 70-76.

2. Hakim TS, Mortola JP. Pulmonary vascular resistance in adult rats exposed to hypoxia in the neonatal period. J Physiol Pharmacol 1990; 68: 419-424.

3. Hampl V, Herget J. Perinatal hypoxia increases hypoxic pulmonary vasoconstriction in adult rats recovering from chronic exposure to hypoxia. Am Rev Respir Dis 1990; 142: 619-624.

4. Levin DL, Mills LJ, Weinberg AG. Hemodynamic, pulmonary vascular, and myocardial abnormalities secondary to pharmacologic constriction of the fetal ductus arteriosus. Circulation 1979; 60: 360-364.

5. Fulton RM, Hutchinson EC, Jones AM. Ventricular weight in cardiac hypertrophy. Br Heart $J$ 1952; 14: 413-420.

6. Hunter C, Barer GR, Shaw JW, Clegg EJ. Growth of the heart and lungs in hypoxic rodents: a model of human hypoxic disease. Clin Sci Mol Med 1974; 46: 375-391. 
7. Herget J, Palecek F. Pulmonary arterial blood pressure in closed chest rats: changes after catecholamines, histamine and serotonin. Arch Int Pharmacodyn Ther 1972; 198: 107-117.

8. McMurtry IF, Morris KG, Petrun MD. Blunted hypoxic pulmonary vasoconstriction in lungs from short-term high altitude rats. Am J Physiol 1989; 56: H849-H857.

9. Hauge A. Conditions governing the pressor response to ventilation hypoxia in isolated perfused rat lungs. Acta Physiol Scand 1968; 72: 33-44.

10. Steel RGD, Torrie JH. Principles and procedures of statistics. 1960.

11. Coceani F, Olley PM. The control of cardiovascular shunts in the fetal and perinatal period. Can J Physiol Pharmacol 1988; 66: 1129-1134.

12. Momma K, Takeuchi H. Constriction of fetal ductus arteriosus by nonsteroidal anti-inflammatory drugs. Prostaglandins 1983; 26: 631-643.

13. Momma K, Hagiwara H, Konishi T. Constriction of fetal ductus arteriosus by nonsteroidal anti-inflammatory drugs: study of aditional 34 drugs. Prostaglandins 1984; 28: 527-536.

14. Momma K, Takao A. In vivo constriction of the ductus arteriosus by nonsteroidal anti-inflammatory drugs in near-term and preterm fetal rats. Pediatr Res 1987; 22: 567-572.

15. Momma K, Konishi T, Hagiwara H. Characteristic morphology of the constricted fetal ductus arteriosus following maternal administration of indomethacin. Pediatr Res 1985; 19: 493-500.

16. Levin D, Hyman A, Heymann M, Rudolph A. Morphological development of the pulmonary vascular bed in experimental fetal hypertension. Pediatr Res 1976; 10: 324 .

17. Levin DL. Morphologic analysis of the pulmonary vascular bed in congenital left-sides diaphragmatic hernia. J Pediatr 1978; 92: 805-809.

18. Levin DL, Fixler DE, Morriss FC, Tyson J. Morphologic analysis of the pulmonary vascular bed in infants exposed in utero to prostaglandin synthetase inhibitors. $J$ Pediatr 1978; 92: 478-483.

19. Tyler T, Leffler C, Cassin S. Use of indomethacin to reverse neonatal hypotension. Experientia 1976; 32: 61.

20. Hislop A, Reid L. New findings in pulmonary arteries of rats with hypoxia-induced pulmonary hypertension. Br J Exp Pathol 1976; 57: 542-554.

21. Permutt S, Riley RL. Hemodynamics of collapsible vessels with tone: the vascular waterfall. $J$ Appl Physiol 1963; 18: 924-932.

22. Finlay M, Suggett AJ, Barer GR. Quantitative changes in the rat pulmonary vasculature in chronic hypoxia: relation to hemodynamic changes. QJ Exp Physiol 1986; 71: 151-163.

23. Haworth SG. Pulmonary vascular remodelling in neonatal pulmonary hypertension: state of the art. Chest 1988; 93 (Suppl.): 133S-138S.

24. Albelda SM. Role of growth factors in pulmonary hypertension. In: Fishman AP, ed. The pulmonary circulation: normal and abnormal. Mechanisms, management, and the national registry. University of Pennsylvania Press. 1990; pp. 201-215.

25. Folkman J. Angiogenesis: what makes blood vessels grow? News Physiol Sci 1986; 1: 199-202.

26. Nakasaka K, Battacharya J, Nanjo S, Gropper MA, Staub NC. Micropuncture measurement of lung microvascular pressure profile during hypoxia in cats. Circ Research 1984; 54: 90-95.

27. Hakim TS, Michel RP, Minami H, Chang HK. Site of pulmonary hypoxic vasoconstriction studied with arterial and venous occlusion. J Appl Physiol: Respirat Environ Exercise Physiol 1983; 54: 1298-1302.

28. Dawson CA, Linehan JH, Bronikowski TA, Riskaby DA. Pulmonary microvascular hemodynamics: occlusion methods. The pulmonary circulation in health and disease. In: Will JA, Dawson CA, Weir EK, Buckner CK, eds. Orlando, Academic Press, 1987; pp. 175-196.

29. Shirai M, Sada K, Niomiya I. Effects of regional alveolar hypoxia and hypercapnia on small pulmonary vessels in cats. J Appl Physiol 1986; 61: 440-448.

30. Tozzi CA, Poiani GJ, Harangoso AM, Boyd CJ, Riley DJ. Pulmonary vascular endothelial cells modulate stretchinduced DNA and connective tissue synthesis in rat pulmonary artery segments. Chest 1988; 93 (Suppl.): 169S-170S.

31. Riley D, Gullo J. Pressure applied to cultured pulmonary artery endothelial cells causes release of a fibroblast mitogen and induces a proto-oncogene. FASEB J 1988; 2: A300. 